\title{
UM MODELO DE GESTÃO INOVADOR VOLTADO PARA A PRATICA PROJETUAL
}

\author{
Julio Monteiro Teixeira \\ Universidade Federal de Santa Catarina \\ juliomontex@gmail.com \\ Eugenio Andrés Díaz Merino \\ Universidade Federal de Santa Catarina \\ eugenio.merino@ufsc.br
}

\begin{abstract}
Resumo: Esta pesquisa apresenta por meio de estudo de caso um modelo inovador de Gestão Visual de Projetos aplicado junto prática projetual de design. Os procedimentos metodológicos incluem uma revisão de literatura dos temas que embasaram a construção do modelo: Desenvolvimento de Projetos, Design Thinking e Gestão Visual; e também a aplicação de tal modelo como estudo de caso. Como resultado são descritos o modelo desenvolvido e a sua aplicação como estudo de caso por meio de dois projetos práticos em disciplina no curso de graduação em design. As considerações finais apresentam potencialidades e novas oportunidades visualizadas após a aplicação do modelo.
\end{abstract}

Palavras-chave: Gestão Visual, Desenvolvimento de Projetos, Design Thinking, Prática Projetual.

\begin{abstract}
This study presents through a case study an innovation model of Project Visual Management applied to design practices. The Methodology Procedures approach a Literature Review about the subjects that supported the model framework: the Project Development, Design Thinking and Visual Management; and an application as a case study. As outcomes are described the model developted and his application as a case study through two applied projects in graduation design courses. The final conclusion shows potentialities and new opportunities noticed after those aplications.
\end{abstract}

Keywords: Visual Management, Product Development, Design Thinking, Design Practices.

\section{INTRODUÇÃO}

O desenvolvimento de projetos tende a diferenciar o produto e torná-lo mais competitivo. Além disso, ele também permite a empresa modificar, melhorar e fortalecer a sua posição frente à concorrência. 
Designers, engenheiros, gestores, empresários, pesquisadores e demais envolvidos no processo de desenvolvimento de projeto, precisam inovar, ser criativos e considerar diferentes perfis e situações em suas propostas, produtos e resultados. Diante disto, a atividade projetual torna-se um dos meios mais adequados de preparar profissionais para esse tipo de processo (BUSSERI e PALMER, 2000; DESIGN STUDIES, 2013). Diante de tal cenário, cabe a indagação: como é possível estimular alunos a considerar e atender tais requisitos de projeto atuando de forma mais participativa durante pratica projetual?

Segundo Sibbet (2013) os seres humanos gostam de interagir, e permitir que as pessoas ponham suas mãos na informação é um caminho direto para maior participação. Equipes podem se tornam mais eficientes e eficazes quando conseguem visualizar o tema de forma que seja possível interagir comparando dados, localizando padrões e mapeando ideias, pois isso facilita a pensar globalmente. (MEREDITH \& MANTEL, 2006; AMARAL et al, 2010; SIBEET, 2013).

No entanto, processos de desenvolvimento mais complexos geralmente são de difícil compreensão e visualização. Pois, implicam em muitas atividades, feitas por diferentes pessoas, cada delas uma produzindo resultados que, por vezes, são utilizados em etapas subsequentes. Dessa forma, a complexidade pode aumentar em razão proporcional ao tamanho, complexidade e especificidades do projeto (BROWNING, 2009; AMARAL et al, 2010). Diante isso, emergiu a possibilidade de desenvolver e posteriormente aplicar, junto a alunos de design, um modelo inovador de gestão de projeto com objetivo de facilitar a interação e monitoramento dos processos projetuais.

Portanto, a aplicação de modelos de gestão de projeto que visem ampliar a visualização, documentação, controle e também estimular a participação e a interação durante a prática projetual mostra-se relevante. Esta pesquisa irá apresentar por meio de estudo de caso um modelo inovador de Gestão Visual de Projetos aplicado junto prática projetual de design.

\section{REVISÃO DE LITERATURA}

Com essa revisão de literatura, buscou-se publicações que contribuíssem para a proposta de Gestão Visual ao voltada ao desenvolvimento de projetos, considerando a aplicação para prática projetual de design.

\subsection{Desenvolvimento de Projetos e o Design Thinking}

Segundo Paladini (2009) denomina-se qualidade de projeto o conjunto de ações práticas que a organização desenvolve para assegurar que os requisitos de mercado sejam atendidos pelas especificações de projeto. A recorrência de uso de determinadas ações práticas em diferentes projetos de produto, configuram o processo de desenvolvimento de projetos de uma organização - seja ele formalmente proposto ou não.

Esse processo consiste em um conjunto de atividades por meio das quais se busca, a partir das necessidades do mercado, das possibilidades e restrições tecnológicas, considerando as estratégias competitivas e de produto da organização, chegar às especificações de projeto de um produto e de seu processo de produção, para que a manufatura seja capaz de produzi-lo (AMARAL et al, 2010). Segundo os autores para obter-se um padrão, no processo de desenvolvimento de projeto, é 
essencial adotar um modelo geral de referencia. No entanto, ao defini-lo deve-se considerar as melhores e mais adequadas práticas.

É neste sentido, que o Design Thinking auxilia diretamente a promoção da gestão visual para o desenvolvimento de produtos, principalmente, por usar ferramentas de linguagem visual para se reconectar com o modo natural de trabalho e descobrir como o processo de brincar, evoluir e fazer versões das coisas - em resumo, trabalhar como designers trabalham - pode auxiliar consideravelmente o processo de desenvolvimento (SIBBET, 2013).

Portanto, a proposta do Design Thinking é apresentar o design como uma ferramenta estratégica para as empresas. Embora o nome "design" seja frequentemente associado à qualidade e/ou aparência estética de produtos, o design como disciplina tem por objetivo máximo promover bem-estar na vida das pessoas. Assim, é a maneira como o designer percebe as coisas e age sobre elas que é proposta como caminho para a inovação empresarial (VIANNA et al, 2012).

\subsection{Gestão Visual}

$\mathrm{Na}$ metade do século XX os japoneses passaram a investigar e sistematizar modelos de gestão direcionados, principalmente, aos procedimentos operacionais fabris.

Concomitante a essa busca por melhores desempenhos foram desenvolvidas propostas que incentivavam a maior participação dos colaboradores no processo, o trabalho em equipe e o uso de instrumentos gerenciais. Os japoneses até hoje induzem seus operários a pensar e a criar. Para isso, incentivam a criatividade e o acesso a informações. Alguns autores são reconhecidos internacionalmente por suas contribuições aos modelos orientais, vale citar: Juran (gestão); Deming (processos); Ishikawa (ferramentas) (PALADINI, 1998).

Desde o inicio, principalmente após a disseminação da filosofia Lean ${ }^{1}$ (que utiliza o gerenciamento visual, mapeamento de fluxo de valor e outros mecanismos visuais), a Gestão Visual tem se mostrado importante por buscar meios rápidos e simples que permitam aos envolvidos saber o estado atual da situação e colaborar com a organização (WOMACCK, 1998; LOCHER, 2008; OSTERWALDER e PIGNEUR, 2010; LEAN INSTITUTE BRASIL, 2012).

O Lean Institute Brasil (2012) define Gestão Visual como um sistema de planejamento, controle e melhoria contínua que integra ferramentas visuais simples que possibilitam o entendimento, e permitam com uma rápida visualização compreender a situação atual. Isso apoia o trabalho padronizado, a aderência dos processos e viabiliza melhorias.

Por finalidade, a Gestão Visual busca permitir aos envolvidos visualização e compreensão, tornando a situação mais transparente, ajudando a focar em processos e a priorizar o que realmente é necessário. Ela pode também, fornecer informações que gerem ações no ponto da comunicação. E a manutenção e atualização de tais informações deve ser feita pelos que realmente fazem o trabalho, que na maioria das

\footnotetext{
${ }^{1}$ A produção enxuta ou manufatura enxuta, em inglês Lean Manufacturing, é também conhecida como Sistema Toyota de Produção, foi criada pelos japoneses da Toyota Motors com o objetivo de reduzir os desperdícios de superprodução, tempo de espera, transporte, movimento e defeitos, gerando maior qualidade, flexibilidade, e redução de tempo e custos, tornando a empresa mais competitiva (WOMACK e JONES, 2004).
} 
vezes são os primeiros a perceber as anormalidades. (Meredith e Mantel, 2006; Osterwalder e Pigneur, 2010; e Lean Institute Brasil, 2012).

As formas de apresentação visuais são ilimitadas, pois os recursos visuais são guiados apenas pelo objetivo de tornar fáceis e acessíveis às orientações, procedimentos e a comparação do desempenho real versus o esperado. Um dos benefícios das apresentações visuais, segundo Eppler e Platts (2009) é que elas podem ser evocativas e, portanto, inspiradoras e cativantes.

A literatura apresenta exemplos práticos de mecanismos visuais, desde níveis estratégicos até os mais operacionais. Entre eles vale mencionar propostas que permitem uma visão global e simplificada do processo: Business Model Generation Canvas (Osterwalder e Pigneur, 2010 e CLARK, 2013); Mapeamento do fluxo de Valor (Locher 2008 e Dennis, 2010); e Método A3 (Lean Institute Brasil, 2012 e Dennis, 2010).

\section{PROCEDIMENTOS METODOLÓGICOS}

Quanto ao desenvolvimento do modelo cabe ressaltar que para presente pesquisa foi realizada previamente uma revisão de literatura dos temas: Gestão Visual, Desenvolvimento de Produtos, Lean, Usabilidade e Design Thinking, que resultaram na indicação de princípios para um Modelo de Gestão Visual de Projetos. E que, tal pesquisa, juntamente com a proposta de funcionamento conceitual do modelo são apresentados aqui e podem ser vistos de forma mais ampla em: Teixeira et al $\left(2012^{\mathrm{a}}\right)$; e Teixeira et al (2012b).

Para investigação em maior profundidade de potencialidades, fragilidades e ajustes necessários ao modelo a ser proposto, a aplicação da pesquisa foi direcionada para estudo de caso. Tal estudo foi realizado durante o segundo semestre de 2012.

Segundo Lakatos e Marconi (2007) o estudo de caso refere-se ao levantamento com mais profundidade de determinado caso ou grupo humano e não pode ser generalizado, por ser caso único. Os autores também esclarecem que, neste tipo de pesquisa são realizados diversos levantamentos e análises, e utilizadas técnicas de observação direta e indireta.

Lakatos e Marconi (2007, p.274), também mencionam características relacionadas ao estudo de caso, que alinham-se bem a essa proposta de pesquisa, são elas:

- 1. visa à descoberta;

- 2. enfatiza a interpretação do contexto;

- 3. retrata a realidade de forma ampla;

- 4. Utiliza diversas fontes de informação;

- 5. permite substituições;

- 6. representa diferentes pontos de vista em dada situação; e

- 7. Faz uso de linguagem simples.

O Modelo de Gestão Visual de Projetos foi aplicado em uma disciplina de graduação denominada: Projeto 15 (Cód.: GR7176 - Turma 04454) que foi ofertada preferencialmente aos alunos do curso de nome do curso e nome da instituição nome retirado para avaliação. A disciplina foi ministrada por 03 professores e auxiliada por alunos de pós-graduação, com 10 alunos de graduação em design organizados em equipes de 03 e 02 integrantes. 
A pesquisa foi autorizada pela Comissão Nacional de Ética em Pesquisa (CONEP), através da Plataforma Brasil. Dessa forma, ela foi avaliada e aprovada pelo Comitê de Ética em Pesquisas com Seres Humanos da Universidade Federal de Santa Catarina, sob o parecer de aprovação número 167.662 divulgado em 10/12/2012 e o acompanhamento do grupo de estudo foi feito diretamente pelos pesquisadores.

\section{RESULTADOS}

Este tópico apresenta uma visão geral e discussões sobre os resultados obtidos no que tange ao Modelo de Gestão Visual de Projetos aplicado ao estudo de caso.

\subsection{Modelo de Gestão Visual de Projetos}

O Modelo de Gestão Visual aqui proposto utilizou como referência em metodologia de design o Guia de Orientação para o Desenvolvimento de Projetos GODP.

O GODP (Figura 1) foi escolhido como base para a aplicação do modelo. Pois, além da familiaridade dos proponentes com o guia e do seu reconhecimento como modelo científico ${ }^{2}$, a proposta estrutural apresenta características relevantes ao conceito de desenvolvimento de projetos e de gestão visual, como: orientação por macro-fases $^{3}$ (inspiração, ideação e implementação), etapas e subetapas; o uso de variação cromática para auxiliar na orientação visual das etapas; e o desenvolvimento cíclico.

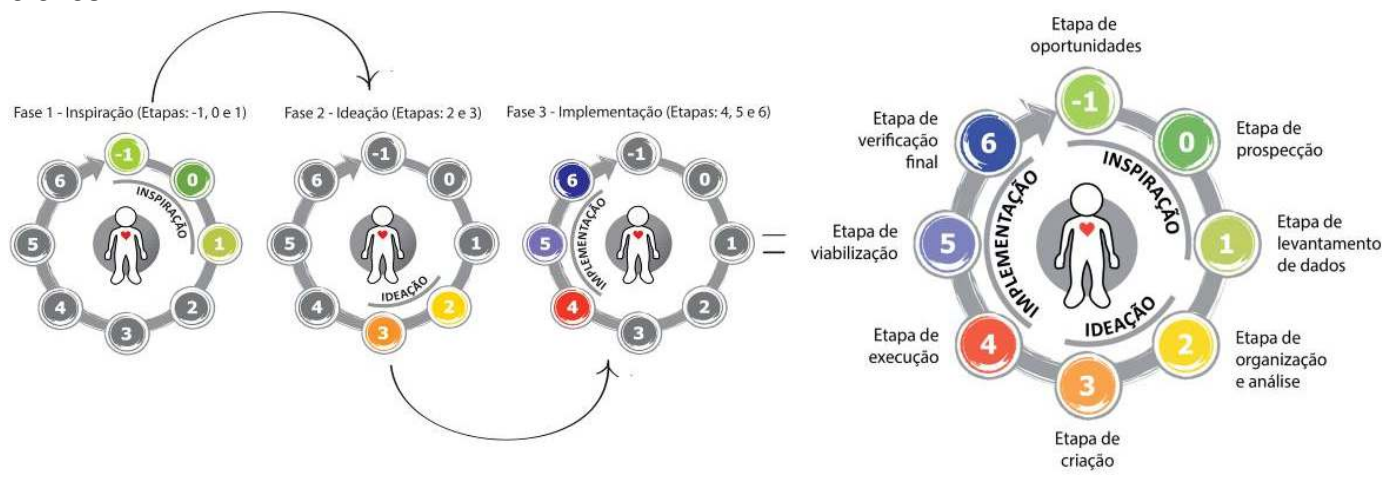

Figura 1 - Guia de Orientação para o Desenvolvimento de Projetos.

Fonte: Autores (2014)

A finalidade do guia nesta pesquisa foi organizar e oferecer uma sequência de atividades de forma flexível, permitindo que o design seja executado de maneira consciente e levando em consideração maior número aspectos relevantes ao projeto.

Para promover fluxo entre etapas, é apresentada aqui uma sistemática com base nos modelos de Back et al (2008) e Amaral et al (2010). O Modelo de Gestão

\footnotetext{
2 Por publicações como: Merino (2010), Merino, Gontijo e Merino (2011), Teixeira (2011).?]

${ }^{3}$ O GODP apresenta 03 macro-fases que se alinham aos modelos e propostas consagrados da literatura, já apresentados anteriormente, entre eles vale citar: Modelo de desenvolvimento de produto de Back et al (2008) composto de Planejamento, Elaboração do Projeto do Produto e Implementação do lote inicial. O Modelo de Referencia do PDP de Amaral et al (2010) que preconiza as macro-fases Prédesenvolvimento, Desenvolvimento e Pós- desenvolvimento; as fases apresentadas pelo Design Thinking em Brown e Wyatt (2010) Inspiração, Ideação e Implementação e ainda em uma publicação de Vianna et al (2012) também relacionada ao conceito de Design Thinking que apresenta os termos Imersão, Ideação e Prototipação.
} 
Visual propõe que, ao terminar uma etapa uma ficha seja preenchida com a função ${ }^{4}$ apresentar uma síntese de informações visuais para que a etapa subsequente possa dar continuidade ao processo de transformação. Um material também foi apresentado aos envolvidos, com função de orientar ${ }^{5}$ a utilização das fichas da etapa anterior, como desenvolver a etapa atual e como preencher sua respectiva ficha de saída.

Esse processo de fluxo visual (Figura 2) atua para fornecer retorno aos envolvidos das etapas: atual, subsequente e anterior. Portanto, ao registrarem a própria ação os envolvidos também geram retorno de informação sobre o desempenho, atividades, etapas e do projeto como um todo, o que é útil para o projeto atual e para projetos futuros.

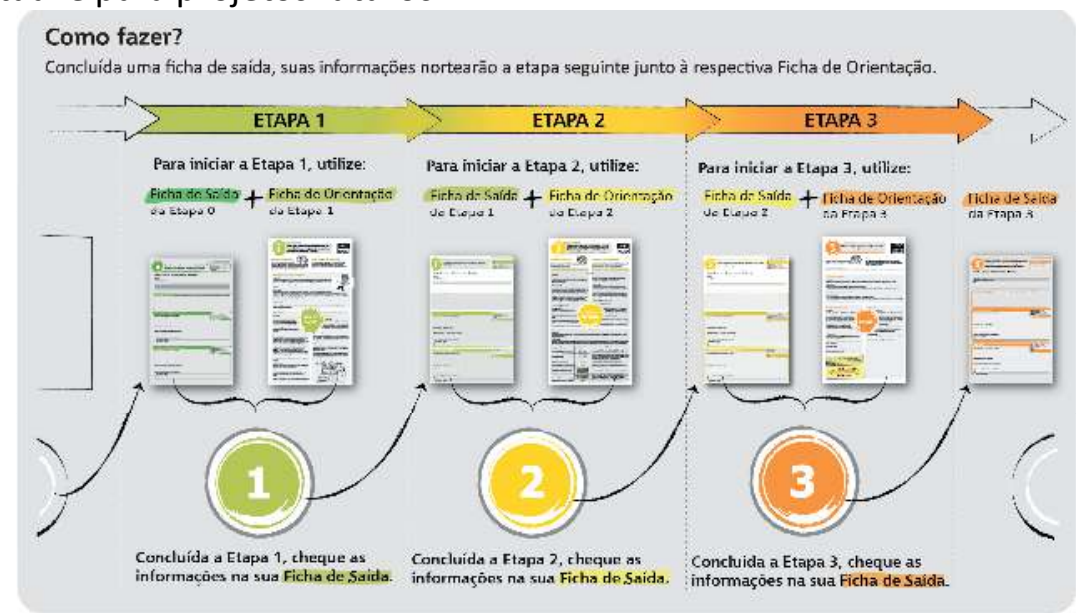

Figura 2 - Fichas de entrada e saída para fluxo entre etapas.

Fonte: Autores (2014)

Como sugere o conceito do Modelo de Gestão Visual de Projetos (TEIXEIRA et al 2012 b), no ambiente de projetos foram instaladas caixas para cada etapa-chave do processo de desenvolvimento de projetos, fichas de orientação, fichas de saída e painéis visuais para o acompanhamento de processos e orientações de apoio.

A imagem a seguir (Figura 4) apresenta as funções das principais do conjunto de ferramentas que dá suporte ao Modelo de Gestão Visual de Projetos.

\footnotetext{
${ }^{4}$ Essa proposta de fichas de saída incorpora a proposta de Amaral et al (2010) de avaliar o que foi desenvolvido (os gates). A diferenciação da proposta aqui apresentada em relação aos demais modelos é que essa orientação seja acessível, sintética e, preferencialmente, visual (ilustrada).

${ }^{5}$ Esse mecanismo reúne características desenvolvidas com base nos Processos de Apoio propostos por Amaral et al (2010) para orientação, desenvolvimento e fluxo de etapas. Lógica também apresentada detalhadamente, no entanto, sob outra perspectiva em Vianna et al (2012). Da mesma forma que na ficha de saída, a diferença da proposta aqui apresentada em relação aos demais modelos é que ela sugere que essa orientação seja sintética e, preferencialmente, visual (ilustrada).
} 
Ferramentas do Modelo de Gestão Visual de Projetos

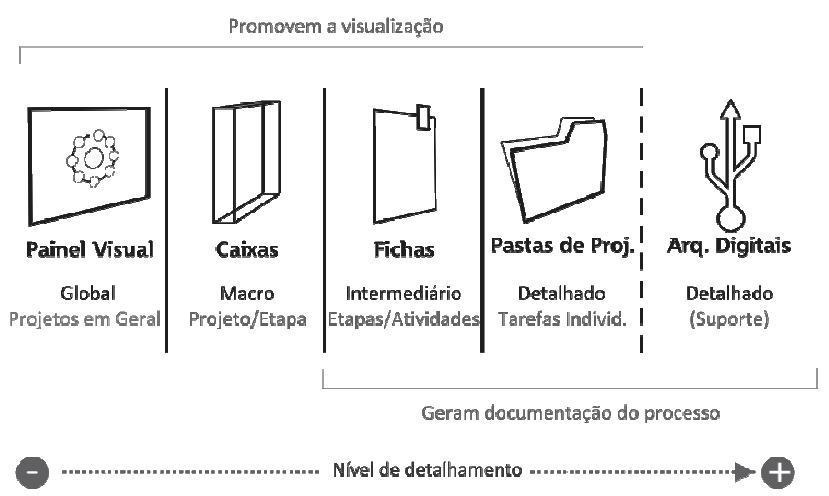

Figura 3: Ferramentas do Modelo de Gestão Visual de Projetos.

Fonte: Autor (2014).

Portanto, o painel visual, as caixas, as fichas e as pastas de projeto promovem maior visualização de informações. E que, fichas, pasta de projeto e os arquivos digitais geram maior documentação para o processo. A representação visual na base da imagem indica que o nível de detalhamento das ferramentas tende a aumentar de forma inversamente proporcional a síntese de informações que a ferramenta promove. Portanto esse conjunto de ferramentas permite que o usuário (projetista, gestor etc.) encontre informações sobre o projeto no nível de detalhamento/síntese que necessita.

Também foi criado um ambiente físico diferenciado com as principais ferramentas do modelo para a equipe de projetos, a proposta baseia-se, que é apresentada por de Suikki; Tromstedt e Haapasalo (2006) em ofertar um espaço diferenciado para dar suporte a Gestão Visual e assim por promover e apoiar a aprendizagem contínua, a cultura de discussão aberta, e consequentemente, proporcionar um bom ambiente em projetos.
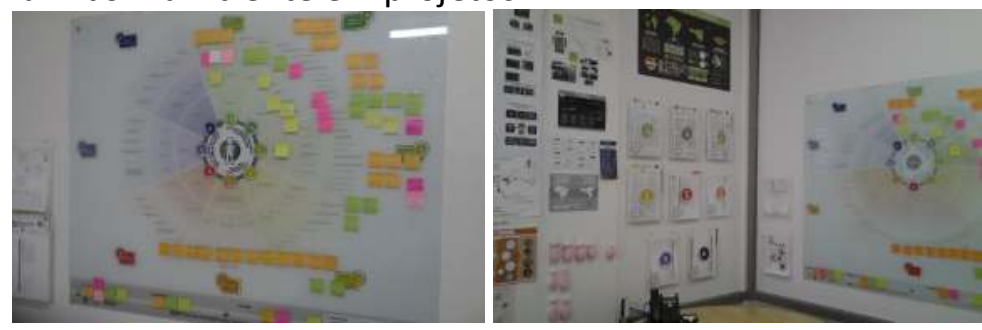

Figura 4: Sala de projeto

Fonte: Autores (2014).

\subsection{Aplicação do Modelo no estudo de caso}

Como já fora dito, o Modelo piloto de Gestão de Projetos foi aplicado como estudo de caso. O cronograma de atividades foi dividido em dois blocos, ou ciclo de projetos, que e foram denominados: Projeto 1 (P1) e Projeto 2 (P2). O P1 foi realizado no início da disciplina e sua porcentagem era de $30 \%$ em relação à composição nota final. Já o projeto P2, de nível mais avançado correspondia a $60 \%$ da nota final. Participação individual completava os $10 \%$ faltantes para a composição da nota final.

O material de apoio foi disponibilizado em uma plataforma online, essa plataforma foi gerenciada pelos professores e assistentes. O material inclua as Fichas de orientação e de saída do GODP, ferramentas de suporte em geral (detalhamentos, 
painéis, modelo de cronogramas etc.), material complementar, modelos de documentos e plano de aulas da disciplina.

O P1 tinha como tema o desenvolvimento de artefatos para uso doméstico direcionados ao preparo de alimentos. Já o P2 ocorreu por meio de uma parceria público-privada com a empresa que atua na área de Telecomunicações, Redes e Segurança eletrônica na região da Grande Florianópolis.

Para o P1 foram disponibilizadas cinco semanas de desenvolvimento e para o P2 dez semanas. O GODP e o Modelo de Gestão de Projetos foram apresentados aos alunos logo nas primeiras aulas. Nesse ínterim, os princípios de funcionamento bem como as ferramentas e suas formas de preenchimento foram esclarecidos.

Após a apresentação inicial da sistemática para o desenvolvimento de projetos do semestre, um "kit de ferramentas" foi entregue para cada equipe de projeto (os alunos foram divididos em quatro equipes de três ou dois alunos cada). O "kit" incluía: uma pasta de projeto (para o acervo material processo de desenvolvimento); um cronograma visual (para organização das atividades); Fichas de orientação e de saída; e uma impressão de $841 \mathrm{~mm}$ x 1189mm do painel visual.

\subsubsection{Aplicação no Projeto 1 (P1)}

Após a apresentação do plano de ensino, cronograma de atividades, GODP e do conjunto de princípios e ferramentas do Modelo, iniciou-se com os alunos um processo de imersão, sem expor claramente ainda, o tema de projeto. Portanto, ao entrarem em sala de aula, os alunos encontraram sobre a mesa diversos utensílios domésticos voltados para o preparo de alimentos.

Durante a primeira etapa do momento de imersão, não foi esclarecido aos alunos forma de uso e finalidade dos utensílios, para que eles pudessem observassem o nível de intuitividade do produto. Na sequência, os alunos utilizaram os produtos no preparo e manipulação de alimentos e foram incitados a higienizá-los posteriormente. Essa dinâmica incitou os alunos a perceberem as oportunidades de projeto, primeira etapa do GODP (Etapa -1).

Após esta a imersão e os esclarecimentos iniciais, equipes e a temática do P1 foram definidas e apresentadas. Em seguida, os alunos estruturaram um cronograma visual inicial (com o modelo de cronograma visual disponibilizado) e realizaram um levantamento preliminar (Etapas -1, 0 e 1 ).

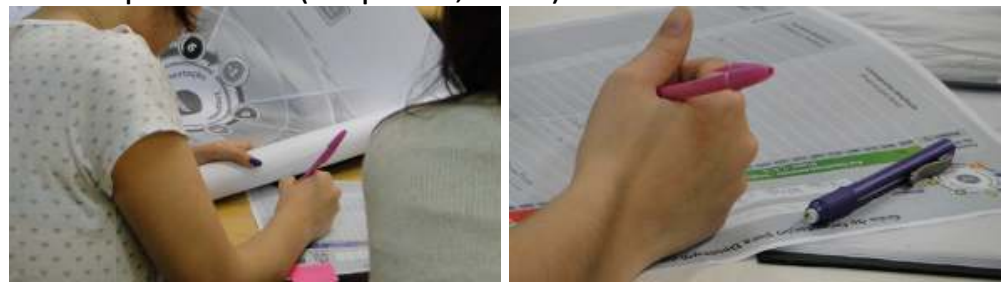

Figura 4: Planejamento e levantamentos preliminares.

Fonte: Acervo - Autores (2014).

As fichas de orientação foram utilizadas como suporte aos alunos no esclarecimento de como poderia ser feito o desenvolvimento de cada etapa, indicando o que é; como fazer; e para que é indicado cada atividade. Além de realizar as atividades, os membros da equipe também se dividiam no gerenciamento das entregas. Tais ações de gerenciamento eram induzidas pelas fichas de entrega, que solicitavam que a equipe planejasse, organizasse e descrevesse suas atividades etapa 
por etapa, indicando inclusive, quem seria o responsável pelo preenchimento da ficha.
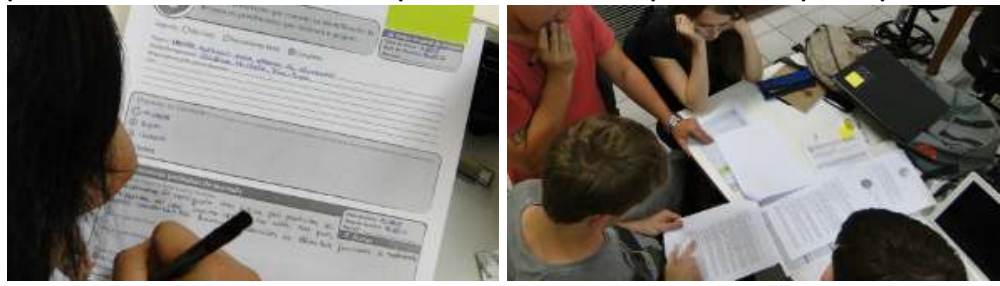

Figura5: Desenvolvimento das etapas iniciais - fase de inspiração.

Fonte: Acervo - Autores (2014).

Para que os alunos compreendessem a importância da utilização do modelo e obtivessem maior facilidade no desenvolvimento das etapas e na transição entre macro-fases, aulas expositivas e atividades complementares foram ofertadas aos alunos pelos professores e assistentes.

$\mathrm{Na}$ etapa de criação (Etapa 3 ) as equipes tiveram a oportunidade de apresentar suas alternativas de projeto de produto para utensílio doméstico de cozinha e além de atividades práticas para estimular a criatividade, também receberam dos professores e assistentes um retorno de como poderiam explorar suas alternativas.

Após o desenvolvimento das alternativas, foram iniciadas as etapas de execução e viabilização (Etapas 4 e 5). Os alunos também fizeram detalhamento técnico de material, estimativas de custo de produção e preparação de documentos para registro de propriedade industrial.
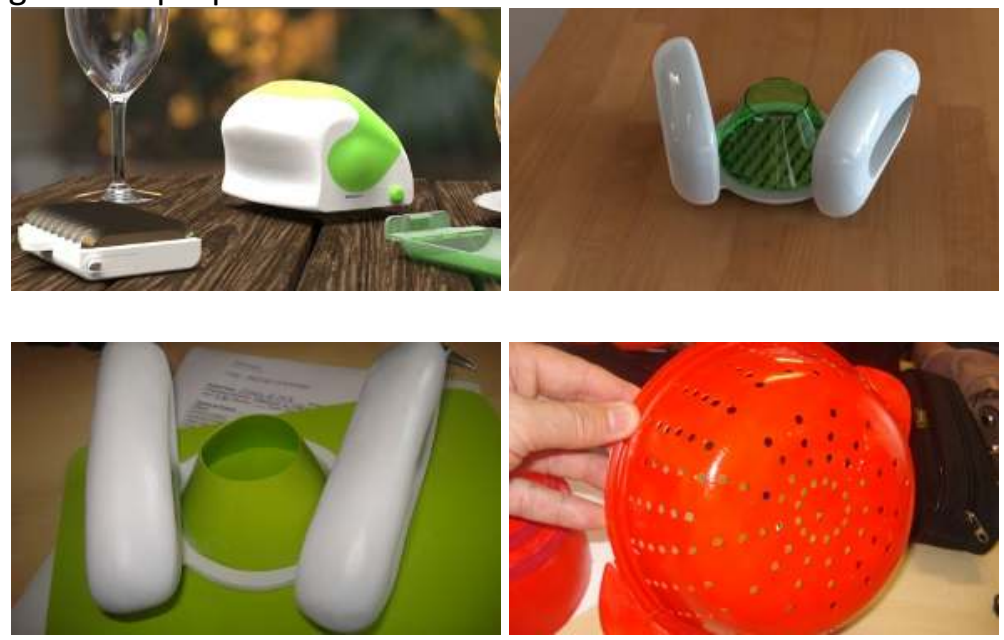

Figura 6: Modelos digitais e físicos do P1.

Fonte: Acervo - Autores (2014).

As equipes apresentaram os resultados do P1 em 10 de outubro de 2012 por meio de argumentação verbal, slides e modelos digitais e físicos. As pastas, arquivos digitais e modelos ficaram com a equipe de professores para avaliação posterior.

Por fim, as avaliações do P1 foram realizadas de forma coletiva, ou seja, com a participação de professores e assistentes. O retorno aos alunos sobre as avaliações dos projetos foi dado por meio de fichas que continham notas, gráficos e comentários.

Após o encerramento do P1 foi solicitado às equipes que mensurassem e apresentassem visualmente como foi à utilização e distribuição do tempo em relação às etapas e subetapas (em tempo real e em porcentagem). Para que os alunos 
levassem em consideração essa experiência como o tempo de desenvolvimento de projetos no momento de estabelecer as estimativas na elaboração do cronograma para o P2. Para isso, eles utilizam como apoio as fichas de entrega que possuem marcações de data de início e término.

\subsubsection{Aplicação no Projeto 2 (P2)}

Como já fora mencionado, o desenvolvimento do Projeto 2 - P2 ocorreu por meio de uma parceria e o tempo de desenvolvimento do P2 fora de dez semanas.

O briefing de projeto foi lido publicamente para as equipes e entregues na versão impressa. Após isso, foram esclarecidos procedimentos a respeito do P2.

Como fora sido trabalhado no P1, na Fase de inspiração (Etapas $-1,0$ e 1) os alunos estruturaram um cronograma inicial e realizaram um levantamento preliminar que foi apresentado em aula pela equipe aos colegas de classe e aos professores e assistentes.

Durante as fases iniciais do P2 notou-se que, além das ferramentas visuais para gestão de projetos já disponibilizadas, as equipes começaram a utilizar e desenvolver outros procedimentos visuais para facilitar a organização das informações provenientes do levantamento preliminar (ver Figura 7-à direita).
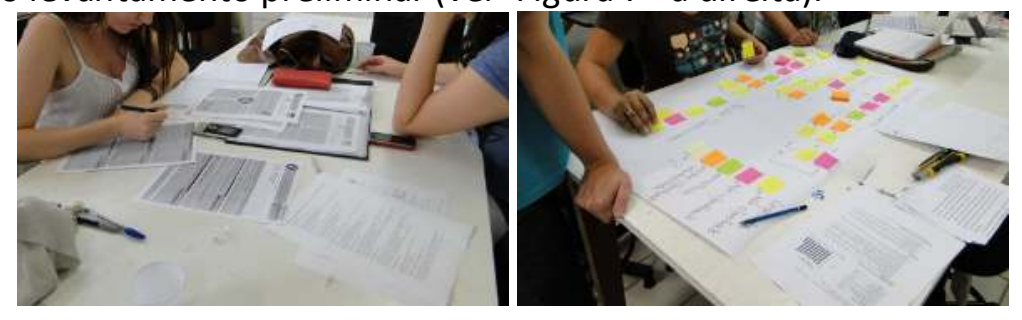

Figura 7: Desenvolvimento do P2 etapas iniciais.

Fonte: Acervo - Autores (2014).

Após a Fase de Inspiração, foi iniciada a Fase de Ideação, onde conceitos e alternativas foram explorados por meio de desenhos e estudos físicos.

A imagem a seguir exemplifica a utilização do painel visual que era aproveitado tanto para os alunos quanto para professores e assistentes, para maior orientação e controle no processo projetual.
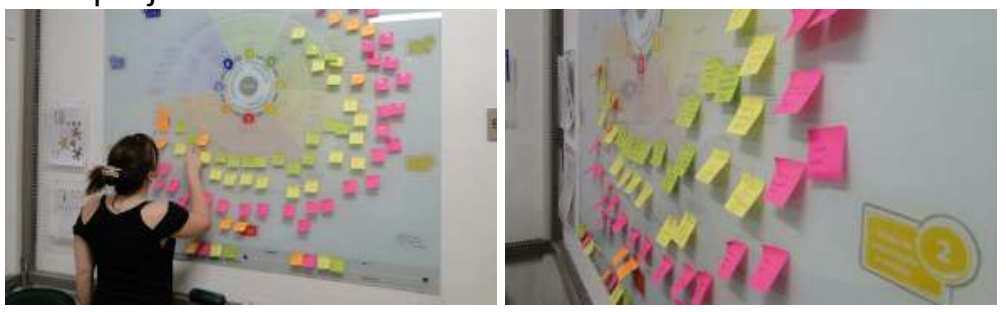

Figura 8: Utilização dos painéis.

Fonte: Acervo - Autores (2014).

As alternativas desenvolvidas pelas equipes foram apresentadas previamente (em nível conceitual) aos demais colegas de classe e aos professores e assistentes. Após essa apresentação preliminar, os alunos receberam orientações dos professores e assistentes para ajustes finais no projeto e também quanto à forma de apresentá-lo. As equipes tiveram uma semana para realizar tais ajustes, e então, mostrar o projeto em uma apresentação final na empresa. 
$\mathrm{Na}$ ocasião, os alunos obtiveram um feedback dos designers e demais profissionais da empresa quanto aos projetos. Na semana seguinte foi realizado o fechamento da disciplina com professores assistentes e alunos. Nesse fechamento houve uma discussão sobre aspectos gerais da disciplina, dos projetos, do método, bem como da sistemática de gerenciamento de projetos.

\section{CONSIDERAÇÕES FINAIS}

A pesquisa apresentou a aplicação de um Modelo de Gestão Visual de Projetos direcionado para facilitar a prática projetual. No entanto, notou-se que o modelo facilita como a condução de projetos em geral, especialmente pode priorizar o sentido da visão. Dessa forma, amplia a participação de diferentes membros da equipe.

Ressalta-se que a gestão visual aplicada ao desenvolvimento de projetos é uma abordagem mais ampla e seus princípios podem ser adaptados para outras metodologias de desenvolvimento de projetos e gestão em geral. Entre os principais diferenciais dessa abordagem cabe destacar, o estímulo para uma cultura e motivação para a visualização e a autogestão.

Cabe destacar ainda que, é função do gerente de projeto (ou do professor) além encorajar autogestão, experimentação e o aprendizado a partir do uso do modelo, e ainda estimular que a equipe reflita sobre como se tornar mais visual.

Além disso, reconhecemos que os recursos de comunicação rápida e Tecnologia da informação - TI atuais permitem praticas interativas. Portanto, como projeto futuro sugere-se dar continuidade por meio do desenvolvimento de aplicativos digitais que possibilitem expor, discutir e compartilhar situações de forma colaborativa e on-line. Pois acredita-se que uma versão digital possa ser agregada ao modelo auxiliando na

orientação, direcionamento de fluxo e, principalmente, no acesso remoto a informações de uma forma fácil, rápida e interativa.

\section{REFERÊNCIAS}

AMARAL, D. et al. Gestão de Desenvolvimento de Produtos: Uma referência para a melhoria do processo. São Paulo: Saraiva, 2010. 542 p.

BACK, N. et al. Projeto integrado de produtos: planejamento, concepção e modelagem. Barueri: Malone, 2008.

BROWN, T., WYATT, J. Design Thinking for Social Innovation. Stanford Social Innovation Review, Winter 2010.

BROWNING, T. R. The Many Views of a Process: Toward a Process Architecture Framework for Product Development Processes. Systems Engineering, v. 12, n. 1, p.6990, 2009.

BUSSERI, M. A; PALMER, J. M. Improving teamwork: the effect of self-assessment on construction design teams. Design Studies, London, maio 2000. p. 223-238. Disponível em: <http://dx.doi.org/10.1016/S0142-694X(99)00024-1>. Acesso em: 05 nov. 2012.

CLARK, T. Business Model You: o modelo de negócios pessoal: o método para reinventar sua carreira. Rio de Janeiro: Alta Books, 2013. 264 p.

DENNIS, P. The remedy: bringing lean thinking out of the factory to transform the entire organization. United States of America: John Wiley \& Sons, Inc., 2010. 
DESIGN STUDIES: Interpreting Design Thinking. Oxford: Elsevier, v. 32, n. 6, nov. 2011. Bimestral. 515-610. Disponível em: <http://www.sciencedirect.com/science/journal/0142694X/32>. Acesso em: 16 abr. 2013.

EPPLER, M e PLATTS, K. Visual Strategizing: The Systematic Use of Visualization in the Strategic-Planning Process. Long Range Planning, [s.I], v. 42, n. 1, p.42-74, 19 jan. 2009. Trimestral. Disponível em: <http://www.sciencedirect.com>. Acesso em: 28 fev. 2012. 2009

LAKATOS, E. e MARCONI, M. A. Metodologia Científica. 5a Edição - São Paulo: Atlas, 2007.

LOCHER, D. Value Stream Mapping for Lean Development process: A How-To Guide for Streamlining Time to Market. New York: Taylor e Francis Group, 2008.

MEREDITH, J. R. e MANTEL, S.J; Project management. 6. ed. New York: Wiley, 2006.

OSTERWALDER, A.; PIGNEUR, Y. Business Model Generation: A handbook for visionaries, game changers and challengers. Wiley John \& Sons, 2010.

PALADINI, Edson. As bases históricas da gestão da qualidade: a abordagem clássica da administração e seu impacto na moderna gestão da qualidade. Gestão \& Produção, São Carlos, v. 5, n. 3, p.168-186, dez. 1998. Disponível em: <http://dx.doi.org/10.1590/S0104-530X1998000300002.>. Acesso em: 27 mar. 2012.

PALADINI, Edson. Gestão Estratégica da Qualidade: Princípios, Métodos e Processos. 2. ed. São Paulo: Atlas. 2009. 220 p.

SIBBET, David. Reuniões Visuais: Como Gráficos, Lembretes Autoadesivos e Mapeamento de Ideias Podem Transformar a Produtividade de um Grupo. Rio de Janeiro: Alta Books, 2013.

SUIKKI, R.; TROMSTEDT, R.; HAAPASALO, H. Project management competence development framework in turbulent business environment. Technovation, [s.I], v. 26, n. 5-6, p.723-738, maio 2006. Bimestral. Disponível em: <http://www.sciencedirect.com>. Acesso em: 28 fev. 2012.

TEIXEIRA, Julio. Identificação e Proteção: o design valorizando grupos produtivos de pequeno porte. 2011. 179 f. Dissertação (Mestrado) - Curso de Pós-graduação em Design e Expressão Gráfica, EGR, UFSC, Florianópolis, 2011.

TEIXEIRA, Julio et al. Gestão visual: uma proposta de modelo para facilitar o processo de desenvolvimento de produtos. In: Conferência Nacional de Integração do Design, Engenharia e Gestão para Inovação, 2., 2012, Florianópolis. Anais. Florianópolis: IDEMi Organization Team, 2012. p. 1-9 a.

TEIXEIRA, Julio et al. Contribuições da Gestão Visual para etapas-chave do processo de desenvolvimento de produtos. In: ERGODESIGN, 12., 2012, Natal. Anais. Natal: Levi/Lexus, 2012. p. $1-8$ b.

VIANNA, M. et al. Design Thinking: Inovação em negócios. Rio de Janeiro: MJV Press, 2012. $161 \mathrm{p}$.

WOMACK, J.P.; JONES, D.T. A mentalidade en xuta nas empresas. 5.ed. Rio de Janeiro: Campus, 1998. 